\title{
O uso do seminário como facilitador no processo de ensino e aprendizagem de linguagens computacionais
}

\author{
Arielly Kizzy Cunha ${ }^{1}$ \\ Anderson Valentino Bozzo ${ }^{2}$ \\ Alexander Vinicius Leite da Silva ${ }^{3}$
}

\begin{abstract}
RESUMO
Neste trabalho, procura-se realizar uma abordagem em relação ao uso da prática pedagógica "Seminário em sala de aula", como instrumento facilitador do processo ensino-aprendizagem na disciplina Lógica de Programação, do Curso Técnico em Informática da Escola Técnica de Praia Grande. O planejamento e a estruturação da aplicação desta prática pedagógica, nos moldes em que foi desenvolvida, basearam-se no Caderno de Orientações do Curso Formação Pedagógica para Educação Profissional e foi fomentado pela observância dos repetidos relatos advindos de alunos de turmas distintas sobre sua dificuldade de aprendizagem das atuais três disciplinas de programação aplicadas no segundo módulo do curso.
\end{abstract}

PALAVRAS-CHAVE: Seminários. Aprendizagem colaborativa. Pesquisa. Educação.

The use of the seminar as a facilitator in the process of teaching and learning computational languages

\begin{abstract}
In this work, an attempt is made to approach the use of the pedagogical practice "Seminar in the classroom", as a facilitator of the teachinglearning process in the Programming Logic discipline, of the Technical
\end{abstract}

\footnotetext{
${ }^{1}$ Doutora em Mídia e Tecnologia. Universidade Estadual Paulista, Bauru, SP, Brasil. Orcid: https://orcid.org/00000001-5155-7210. E-mail: ariellykizzy@gmail.com.

${ }^{2}$ Especialista em Docência para Ensino Técnico. Centro Paula Souza, FATEC, Praia Grande, SP, Brasil. Orcid: https://orcid.org/0000-0001-5567-5329.E-mail: analistaandersonbozzo@gmail.com.

${ }^{3}$ Graduando em Letras. Bolsista PIBID/CAPES. Centro Universitário Sagrado Coração, Bauru, SP, Brasil. Orcid: https://orcid.org/0000-0002-4672-8799. E-mail: $\underline{\text { alexandervinicius.s@ gmail.com. }}$
} 
Course in Informatics at the Technical School of Praia Grande. The planning and structuring of the application of this pedagogical practice, along the lines in which it was developed, was based on the Guidance Notebook of the Pedagogical Training Course for Professional Education and was fostered by observing the repeated reports from students of different classes about their difficulty in learning the current three programming disciplines applied in the second module of the course.

KEYWORDS: Seminars. Collaborative learning. Search. Education.

El uso del seminario como facilitador en el proceso de enseñanza y aprendizaje de lenguas computacionales

\section{RESUMEN}

En este trabajo se intenta acercar el uso de la práctica pedagógica "Seminario en el aula", como facilitador del proceso de enseñanzaaprendizaje en la disciplina Lógica de Programación, del Curso Técnico en Informática de la Escuela Técnica de Praia Grande. La planificación y estructuración de la aplicación de esta práctica pedagógica, en la línea en la que se desarrolló, se basó en el Cuaderno de Orientación del Curso de Formación Pedagógica para la Educación Profesional y se impulsó a partir de la observación de los repetidos informes de estudiantes de diferentes clases sobre su dificultad en aprender las tres disciplinas de programación actuales aplicadas en el segundo módulo del curso.

PALABRAS CLAVE: Seminarios. Aprendizaje colaborativo. Buscar. Educación.

$$
* * *
$$

\section{Introdução}

O presente artigo objetiva analisar a relevância da aplicação de seminário na qualidade de trabalho em grupo com foco na aprendizagem colaborativa em 'Lógica de Programação', disciplina do primeiro módulo do curso de Técnico em Informática do Centro Paula Souza, responsável por 
introduzir aos alunos os conceitos, estruturas e bases tecnológicas congruentes às linguagens de programação computacional.

De acordo com Severino (1993) os objetivos do seminário são, entre outros, aprofundar as reflexões sobre um problema, analisar de forma mais rigorosa e radical o texto ou tema, efetuar leitura com a perspectiva de julgamento e de crítica, e discutir a problemática presente explícita ou implícita do texto.

Segundo Severino (2002), os trabalhos didáticos exigidos, sobretudo, nos cursos de graduação, seguem um caráter universal de estruturação lógica e de organização metodológica, ou seja, são procedimentos que ainda fazem parte intrínseca da formação técnica ou científica do estudante. Os trabalhos, desde então, segundo o autor, dependerão "principalmente de seus objetivos e de natureza do próprio objeto abordado, assim como em função de exigências específicas de cada área do saber humano" (SEVERINO, 2002, p. 129).

O desenvolvimento e a apresentação de seminário é uma metodologia de estudo que favorece a percepção de novas ideias, novas questões e perspectivas, "o objetivo do seminário é levar todos os participantes a uma reflexão aprofundada de determinado problema, a partir de textos e em equipe" (SEVERINO, 2002, p. 63).

Para que o uso do seminário seja produtivo, sugere-se que:

- Seja aplicado como um método didático-pedagógico essencial para estudantes;

- Grupos de estudo sejam divididos e coordenados;

- Recebam orientação quanto ao material de trabalho;

- Elaborem pesquisa, texto didático e um texto roteiro a ser apresentado para todos os presentes na sala: professor e ouvintes;

- Os alunos sejam estimulados a participar e interagir, inclusive da discussão final; 
- Organizem os recursos necessários e as técnicas de apresentação do trabalho;

- Desenvolvam esquema de um seminário e organizem conteúdo a ser apresentado e tempo;

- $\mathrm{Na}$ apresentação demonstrem conhecimento sobre o tema da apresentação;

- Após a finalização da apresentação, momento para a reflexão e discussão com a mediação do professor;

- Ir além do material apresentado pelo professor, explorando diversas fontes e referenciais;

- Entendimento coletivo e elaborado do conteúdo da apresentação do tema;

- Compreensão da mensagem numa perspectiva crítica.

Conforme o Plano de Curso estipulado pelo Centro Paula Souza, a esta disciplina está incumbida a responsabilidade do desenvolvimento das seguintes competências: "Desenvolver e interpretar algoritmos, fluxograma e pseudocódigos para codificar programas."

Nestes termos, a qualidade de escolha e aplicação dos procedimentos didáticos visando o bom aproveitamento desta disciplina pelo corpo discente é fundamental, posto que esta se trate de embasamento teórico metodológico rigorosamente necessário para a compreensão das posteriores disciplinas deste curso especificamente voltadas ao desenvolvimento de sistemas computacionais.

Diante do exposto, visando trazer maior interação entre os alunos e buscando fortalecer-lhes no entendimento da importância de seu protagonismo na construção do próprio conhecimento, foi escolhida como um dos procedimentos didáticos, a aplicação da prática pedagógica de seminário em sala de aula.

O protagonismo do aluno favorece e possibilita o desenvolvimento da sua autonomia, porque se sentirá motivado a buscar conhecimentos de 
forma independente, neste caso o professor atuará como mediador do processo de ensino e aprendizagem. O protagonismo em sala contribui para aulas dinâmicas, com estimulando a participação dos discentes, a criatividade nos estudantes, estimulando a formação de um indivíduo crítico, inventivo, criativo, comunicativo e inovador.

Para se reproduzir e reproduzir a estrutura social onde se insere, a escola não pode limitar-se a assegurar a sua reprodução. Ela tem de produzir inovações, tem de reproduzir na inovação e reproduzir inovações. Inovações que sejam parcelares, segmentares, racionais, e controladas e cuja introdução não questione o contexto institucional em que são concebidas, em suma, inovações que não sejam inovantes, que não desencadeiem um movimento "incontrolado" e "irracional" de produções de inovações (CORREA, 1989, p. 14).

\section{Objetivos}

Como objetivo geral, aspirando dinamizar o processo de ensinoaprendizagem do conteúdo específico da disciplina com a diversificação dos procedimentos pedagógicos, foi realizada a escolha da prática pedagógica de seminário em sala de aula, justamente por ser uma prática pedagógica incomum em aulas de algoritmos e lógica computacional e pelo entendimento de que a aplicação adequada desta prática traria resultados expressivos, agregando conhecimento útil e diversificado aos alunos.

Como objetivos específicos, enumeram-se os seguintes:

- O fomento à pesquisa no desígnio de treinar e desenvolver o protagonismo no aprendizado dos alunos;

- Viabilizar aos alunos uma reflexão holística acerca dos conteúdos e contextos das bases tecnológicas estudadas durante o semestre, de forma a evidenciar-lhes que, a este ponto, já terão adquirido o conhecimento necessário e desenvolvido a capacidade de aprender 
qualquer outra nova linguagem de programação computacional que lhes seja apresentada.

- Permitir um primeiro contado com as linguagens de programação mais comuns do mercado, promovendo mais segurança emocional ao aluno que terá de estudar e aprender, além de novos paradigmas computacionais contemplados no Plano de Curso, três linguagens de programação distintas ao longo do segundo módulo;

- Impactar positivamente na diminuição da evasão escolar devido aos elementos supracitados.

\section{Referencial Teórico}

Conforme o artigo "Seminários de Pesquisa e Extensão da UEMG", disponibilizado no portal da Universidade do estado de Minas Gerais, a pesquisa ensina o aluno a raciocinar e a enfrentar novos desafios e os seminários possibilitam o livre trânsito da pesquisa com o ensino e a extensão, pois a pesquisa atua na fronteira do conhecimento. Assim, conclui que os seminários são a melhor maneira de despertar o aluno para a vida acadêmica, uma vez que o aluno-pesquisador, ao preparar sua apresentação, está desenvolvendo uma série de habilidades que lhe serão úteis na vida profissional.

A convergência mútua entre professor e aluno como permuta de saber e participação social no espaço de aprendizado promovem papel essencial na formação profissional do educando. Por isso, o professor na qualidade de mediador, deve estar atento na identificação de informações que lhe permitam verificar o aprendizado do aluno e em paralelo proporcionem formas de colaborar, promovendo o retorno quando necessário e possibilitando inclusive a auto-avaliação dos alunos, no ensejo de conduzi-los da melhor forma possível nos caminhos do saber. 
O seminário (cuja etimologia está ligada a semente, sementeira, vida nova, ideias novas) é uma técnica riquíssima de aprendizagem que permite ao aluno desenvolver sua capacidade de pesquisa, de produção de conhecimento, de comunicação, de organização e fundamentação de ideias, de elaboração de relatório de pesquisa, de forma coletiva (MASETTO, 2010, p. 111).

A utilização de seminário como ferramenta avaliativa que possibilita ao aluno desenvolver competências e habilidades no que se refere à pesquisa, à liberdade na busca de conhecimento, à expressão e o posicionamento crítico/reflexivo no decorrer da metodologia de organização e resultado do afazer proposto, contribuindo para o desenvolvimento da capacidade de discussão, o exercício interpretativo a partir de diferentes perspectivas teóricas e práticas, a promoção do trabalho em grupo e suas contribuições para o alcance da percepção do outro, situações estas que favorecem o bom desempenho profissional, hoje fundamentado no trabalho em equipe.

Para que haja o uso assertivo do seminário como ferramenta de forma assertiva para o ensino, o docente precisa estar apto a aplicar a metodologia. Para Oliveira Costa, Ramos dos Santos, Lima Martins (2020) a formação contínua e efetiva dos professores é uma possibilidade de reflexão, atualização, aprofundamento de saberes e práticas, interação com novos conhecimentos, desenvolvimento de experiências e ampliação de competências profissionais.

[...] pensar a formação docente na atualidade é atentar para o fato de que esta deve atender aos desafios e necessidades postos. Para tanto, torna-se importante que o professor seja formado de modo que possa articular seus conhecimentos mediante ação reflexão teórico-prática. Pensada desse modo, a formação docente remete-se à reflexão da prática educativa voltada ao desenvolvimento da autonomia tanto do professor quanto do aluno (OLIVEIRA COSTA; RAMOS DOS SANTOS; LIMA MARTINS, 2020, p. 1194). 
A formação continuada do professor é um processo educacional, nele o docente é agente e sujeito de sua prática, é responsável pela construção e do conhecimento, através do estímulo ao desenvolvimento cognitivo dos discentes.

[...] essa formação deve possibilitar ao docente trabalhar com o conhecimento de um modo que transcenda o ensino e que alcance uma atualização científica, pedagógica e didática que lhe permita criar espaços de participação, discussão e reflexão em suas próprias atividades profissionais. Desse modo, proporcionando aos alunos condições de lidar com as realidades sociais em que se encontram inseridos, sendo capazes de analisá-las e de agir de modo autônomo e consciente sobre elas. Sendo assim, o ensinar reveste-se de um teor político e, por conseguinte, inexistente sem o aprender, tal qual este também se anula sem aquele (OLIVEIRA COSTA; RAMOS DOS SANTOS; LIMA MARTINS, 2020, p. 1196).

Para os autores, o professor é responsável pela sua tarefa de pesquisador buscando informações que acompanhem as mudanças históricas, culturais e sociais, a fim de fornecer ensino de acordo com as necessidades dos alunos e capacidades exigidas, destaca-se o perfil de problematizador da aprendizagem, e mediador do conhecimento para a formação, inclusive, profissional, estimulando a autonomia do aluno.

Com esse diálogo, de acordo com a definição de Freire (1996):

[...] nas condições de verdadeira aprendizagem os educandos vão se transformando em reais sujeitos da construção e da reconstrução do saber ensinado, ao lado do educador, igualmente sujeito do processo. Só assim podemos falar realmente de saber ensinado, em que o objeto ensinado é apreendido na sua razão de ser e, portanto, aprendido pelos educandos (FREIRE, 1996, p. 13).

A relação pedagógica fundamenta-se no diálogo, na troca, na relação e no entendimento entre docente e discente, de acordo com Freire (1996) características primordiais para consolidação de uma pedagogia autônoma que supere o autoritarismo em sala de aula, fomentando uma horizontalidade e aproximação entre professor e aluno. 


\title{
Metodologia
}

Neste estudo, a metodologia usada foi abordagem qualitativa, realizada a partir de pesquisa bibliográfica. As bases teóricas - metodológicas desse projeto baseiam-se em pesquisa-ação. Segundo Minayo (1995, p. 22-23):

\begin{abstract}
A pesquisa qualitativa responde a questões muito particulares. Ela se preocupa nas ciências sociais, com o nível de realidade que não pode ser quantificado. Ou seja, ela trabalha com o universo de significados, motivos, crenças, valores e atitudes, o que corresponde a um espaço mais profundo das relações, dos processos e dos fenômenos que não podem ser reduzidos à operacionalização de variável.
\end{abstract}

Para Minayo (1995) a pesquisa qualitativa responde questões particulares e das ciências sociais, quando a realidade que não pode ser quantificada, assim, trabalha com universo significativo, por exemplos: aspirações, crenças, valores, temas das relações humanas e fenômenos que não podem ser reduzidos à operacionalização de variáveis. A diferença entre a pesquisa qualitativa e a pesquisa quantitativa é de natureza e o conjunto de dados quantitativos e qualitativos não se opõem, na verdade são complementares e interagem dinamicamente. A pesquisa qualitativa investiga os fatos através da observação e o contato contínuo ou frequente com o grupo que pesquisa.

Desta forma a pesquisa desenvolveu um trabalho que reflete acerca do protagonismo discente e como essa prática inovadora pode mudar e contribuir para o professor-aluno a fim de promover uma aprendizagem significativa e prazerosa. Freire (1996) defende que o ensino seja baseado numa pedagogia da autonomia, e desta forma compreender que a educação é intervenção no mundo, sua prática não é neutra, é definida, intencional. Para o autor, uma pedagogia da autonomia depende de experiências que estimulam a tomada de decisão e a responsabilidade, e o diálogo, pois através da relação dialógica o sujeito se relaciona com o mundo. 
Freire (1996) propõe saberes sem os quais o educador não terá uma prática educativo-crítica, descrevendo-os detalhadamente e refletindo sobre a postura sua postura dos educadores com seus educandos, tratando desta relação bidirecional, da prática da curiosidade, como uma inquietação do saber e como uma base da postura dialógica, essencial para se construir o conhecimento.

Com base nessas premissas, a pesquisa traz que a execução dos trabalhos sugeridos aos alunos foi realizada em grupos, assim como sua avaliação. O procedimento como um todo, desenvolveu-se no sentido de demonstrar a relevância do seminário como prática pedagógica que incremente o aprofundamento teórico-conceitual a partir da pesquisa.

A partir do início do semestre, a disciplina de algoritmos foi trabalhada com um programa de apoio chamado VisuAlg. Segundo definição explicitada no site do próprio desenvolvedor da ferramenta, "O VisuAlg é um programa que edita, interpreta e executa algoritmos com uma linguagem próxima do português estruturado como um programa normal de computador". Com esta ferramenta de apoio, foram trabalhadas todas as Bases Tecnológicas práticas do Plano de Curso descritas no Plano de Trabalho Docente:

- Definição e criação de Variáveis e Constantes;

- Operadores Aritméticos e Expressões Aritméticas;

- Operadores Relacionais;

- Operadores Lógicos e Expressões Lógicas;

- Comandos de Entrada, Processamento e Saída;

- Funções pré-definidas;

- Estruturas de Controle: Sequencial; Condicional; Repetição;

- Vetores e Matrizes;

- Procedimentos e Funções.

Realizada como atividade para composição de menção final, a prática pedagógica Seminário em sala de aula, como instrumento facilitador do processo ensino-aprendizagem na disciplina Lógica de 
Programação, além da intrínseca pesquisa bibliográfica e documental, foi segmentada em quatro elementos principais:

1. Apresentação e explicação da prática pedagógica para os alunos;

2. Desenvolvimento do trabalho escrito dentro do modelo fornecido;

3. Desenvolvimento do meio de apresentação, com slides ou demonstração direta de aplicação dos conceitos nas Interfaces de Desenvolvimento específicas para cada linguagem (IDE);

4. Apresentação em sala de aula.

\section{Apresentação e explicação da prática pedagógica para os alunos}

O planejamento desta prática pedagógica começou a ser realizado logo após o primeiro encontro presencial do Programa Especial de Formação Pedagógica de Professores para Educação Profissional. Nos dias sequentes ao encontro, foram consultados o coordenador e os outros professores da área de informática da unidade escolar, a fim de idealizar um projeto de real valia aos alunos.

$\mathrm{Na}$ primeira aula da disciplina em junho, já com a concepção do projeto concluída, foi solicitado à turma 1IF3 (primeiro módulo noturno do curso técnico em informática do primeiro semestre de 2017) que se organizassem em grupos para a realização desta atividade e lhes foi informado que este trabalho deveria ser entregue e apresentado no último dia de aula da disciplina no semestre.

Foi realizada a explicação e demonstração um exemplo passo a passo de como deveriam ser realizados a documentação escrita e como conseguir atender aos itens solicitados como conteúdo do seminário. Para este exemplo, foi escolhida a linguagem Visual Basic 6, uma linguagem de programação antiga (em termos computacionais), que há alguns anos encontra-se em desuso comercial, devido ao advento de tecnologias mais modernas, mas que se adequava perfeitamente ao proposto, inclusive por conta da simplicidade de sua sintaxe. 
De acordo com o site da Microsoft (2020) é uma linguagem de programação orientada a objeto desenvolvida pela Microsoft e lançada em 1991. Quando o Visual Basic 1.0 foi lançado, Bill Gates, presidente e CEO da Microsoft, descreveu-o como um ambiente ideal para programação naquela década. Em 7 de novembro de 2005, a Microsoft lançou o Visual Studio 2005, que incluiu oito Visual Basic e o .NET Framework versão 2. Em 27 de fevereiro de 2008, a Microsoft lançou o Visual Studio 2008, incluindo Visual Basic 9 .NET Framework versão 3.5. Em 12 de abril de 2010, a Microsoft lançou o Visual Studio 2010 e o Framework versão 4.

De acordo com a Microsoft (2020), o uso de Visual Basic torna rápido e fácil a criação de aplicativos .NET de tipo seguro e é parte integrante do pacote Microsoft Visual Studio. Sua versão mais recente faz parte do pacote Visual Studio .NET, voltada para aplicações .Net. Sua versão anterior fez parte do Microsoft Visual Studio 6.0, ainda muito utilizado atualmente por aplicação estruturada, imperativa, declarativa, orientação a objeto, ou seja, a Programação Orientada a Objetos é uma programação baseada no conceito de "objetos", que podem conter dados na forma de campos, os atributos, e códigos, na forma de procedimentos, os métodos.

$\mathrm{Na}$ atividade observada na pesquisa, cada grupo precisaria pesquisar a origem e histórico de uma das linguagens de programação propostas, mostrando exemplos de execução e sintaxe, realizando comparativos entre o aprendido e utilizado durante o semestre em sala de aula, com a linguagem pesquisada no trabalho. As linguagens elencadas para a execução deste trabalho foram C\#, JAVA, PHP, LUA e PHYTON e cada grupo ficou responsável pela apresentação de uma delas.

\section{Desenvolvimento do trabalho escrito}

O desenvolvimento da parte escrita do trabalho tinha como exigência, preencher um formulário robusto, com tabelas de comparativos entre a linguagem educacional a aprendida em sala de aula com as estruturas, 
sintaxe e operadores de todas as linguagens elencadas para o trabalho, dentro do modelo fornecido, contemplando os seguintes itens:

- Como fazer um comentário;

- Como concatenar strings (ou conteúdos de variáveis);

- Terminador de statement (linha de comando) / Separador de estruturas;

- Declaração de Variáveis;

- Atribuição de valores em Variáveis;

- Tipos de dado;

- Operadores Matemáticos, Operadores Relacionais, Operadores Lógicos;

- Entrada e Saída de dados;

- Estruturas de decisão;

- Seleção Múltipla;

- Estruturas de repetição;

- Vetores e Matrizes;

- Procedimentos e Funções.

\section{Desenvolvimento do meio de apresentação}

As orientações do trabalho foram passadas por meio de aula expositiva, com exemplo de apresentação e explicação do modelo de relatório, também enviado por e-mail para o representante de sala. Cada grupo ficou livre para produzir e conduzir sua própria apresentação, com tempo máximo de 15 minutos.

\section{Apresentação em sala de aula}

Desde o princípio, os grupos foram avisados de que cada aluno deveria concentrar-se em suas potencialidades, contribuindo ativamente para um bom trabalho em equipe, que seria fundamental para a obtenção de um resultado final de qualidade profissional. Para a avaliação e a atribuição de 
menção aos trabalhos, seriam realizadas análises globais, focando no resultado e qualidade do trabalho final de cada grupo.

\section{Resultados e Discussão}

Cada grupo ficou responsabilizado por uma linguagem específica para as apresentações e o tempo de execução (entre quatro a cinco semanas) seria curto para que cada grupo cumprisse todas as exigências do trabalho, pesquisando uma por uma das linguagens. Sendo assim, mesmo não explicitado, o comportamento colaborativo entre grupos e a troca de informações era esperado e desejado.

O resultado foi extremamente positivo sob este aspecto, uma vez que a turma demonstrou uma enorme capacidade de trabalho em equipe, produzindo de forma colaborativa tudo o que foi solicitado: Todos os grupos apresentaram a parte escrita completa e dentro dos padrões solicitados.

Conforme o combinado com os alunos, os grupos tiveram total liberdade para escolher como seriam suas apresentações no dia de aplicação do seminário. Com isso, obteve-se uma variedade de cores, formatos e cadências, enriquecendo ainda mais experiência de intercâmbio de conhecimentos e prendendo a atenção do restante da turma.

\section{Considerações}

Baseando-se nos resultados obtidos com a aplicação desta prática pedagógica, acredita-se no potencial estimulador de pesquisa e debate crítico que o seminário como procedimento pedagógico adequadamente orientado pode vir a proporcionar no processo de aprendizagem do aluno do ensino técnico.

Em relação ao proposto nos objetivos deste trabalho, é factível a observância do atendimento às todas as expectativas do projeto, ratificando a viabilidade e a importância do uso de seminário em sala de aula como prática pedagógica e avaliativa para a disciplina de Lógica de Programação, 
reforçando o entendimento da importância do papel mediador do professor, da axiomática necessidade do desenvolvimento das habilidades de interação social e do trabalho em equipe, bem como o eminente valor educacional dos seminários e da aprendizagem-colaborativa.

\section{Referências}

CORREA, J. A. Inovação pedagógica e formação de professores. Porto: Edições ASA. 1989.

FREIRE, P. Pedagogia da autonomia: Saberes necessários à prática educativa. 25. ed. São Paulo: Paz e Terra, 1996.

MASETTO, M. T. Competência pedagógica do professor Universitário. São Paulo: Summus, 2012.

HUHNE, L. M. Metodologia cientifica: caderno de textos e técnicas. 7. ed. Rio de Janeiro: Agir, 2001

MASETTO, M. T. O professor na hora da verdade: a prática docente no ensino superior. São Paulo: Avercamp, 2010.

MICROSOFT. Visual Basic. Disponível em: https://docs.microsoft.com/ptbr/dotnet/visual-basic. Acesso em: 10 set. 2020.

MINAYO, M. C. S. Pesquisa social: teoria, método e criatividade. 18. ed. Petrópolis: Vozes, 1995.

OLIVEIRA COSTA. A. L. O. C.; RAMOS DOS SANTOS, A. R. S.; LIMA MARTINS J. L. M. A formação docente: por uma prática educacional libertadora. Revista Ibero-Americana de estudos em educação, Araraquara, v. 15, n. 3, jul./ set. 2020. DOI: https://doi.org/10.21723/riaee.v15i3.12511.

PORTAL DA UNIVERSIDADE DO ESTADO DE MINAS GERAIS. Seminários de Pesquisa e Extensão da UEMG. 2017. Disponível em: http://www.uemg.br/pesquisa_seminarios.php. Acesso em 29 jul. 2018.

SEVERINO, A. J. Diretrizes para elaboração de um seminário. Metodologia do trabalho científico. 19. ed. São Paulo: Cortês, 1993. cap. 4, p. 59-66. 